\title{
In vivo $\beta_{3}$-adrenergic stimulation of human thermogenesis and lipid use
}

\begin{abstract}
Objective: To investigate the role of the human $\beta_{3}$-adrenergic receptor in in vivo isoproterenol (IN N, isoprenaline)-induced thermogenesis and lipid use.

Methods E ight male volunteers participated in two studies. In the first study subjects received oral dosages of $2.5,7.5,15$, and $40 \mathrm{mg}$ nadolol or propranolol (both $\beta_{1^{-}}$and $\beta_{2}$-adrenergic receptor antagonists) at random, after which isoproterenol $\left(\beta_{1^{-}}, \beta_{2^{-}}\right.$, and $\beta_{3^{-}}$-adrenergic receptor agonist) was infused in an individually determined dosage (range, 19 to $35 \mathrm{ng} / \mathrm{kg} \cdot \mathrm{min}$ ) that increased energy expenditure by $25 \%$ without pretreatment. In the second study, 50, 100, and $200 \mathrm{ng} / \mathrm{kg} \cdot \min$ isoproterenol or saline solution were infused after pretreatment with $80 \mathrm{mg}$ nadolol. In both studies energy expenditure and respiratory exchange ratio were measured by indirect calorimetry and, at the end of each infusion period, blood samples were taken and tremor score (only first study), heart rate, and blood pressure were measured.

R esults. In the first study, nadolol or propranolol in doses $\leq \mathbf{4 0} \mathbf{m g}$ could not fully block $\beta_{1}$-adrenergic receptor-mediated increases in heart rate and systolic blood pressure. Propranolol in doses $\leq 7.5 \mathrm{mg}$ could not fully block the $\beta_{2}$-adrenergic receptor-mediated increase in tremor score during isoproterenol infusion. The increases found in thermogenesis and lipid use could therefore be explained by concomitant $\beta_{1}$ - and $\beta_{2}$-adrenergic stimulation. In the second study, isoproterenol infusion induced a significant increase in heart rate, but no increases in thermogenesis and lipid use were found compared with infusion of saline solution.

Conclusi on: $\mathrm{No}$ evidence could be found for a $\beta_{3}$-adrenergic receptor-mediated increase in human thermogenesis and lipid use during isoproterenol infusion after pretreatment with nadolol or propranolol. (Clin Pharmacol Ther 2000;67:558-66.)
\end{abstract}

Sandra L. H . Schiffelers, M Sc, Ellen E. Blaak, PhD, Wim H . M. Saris, PhD, and Marleen A. van Baak, PhD Maastricht, The N etherlands

The sympathetic nervous system plays an important role in energy and substrate metabolism. The effects of the sympathetic nervous system are mediated by $\alpha$ - and $\beta$-adrenergic receptors. $\alpha$-Adrenergic stimulation does not affect whole-body thermogenesis, 1,2 whereas nonselective $\beta$-adrenergic stimulation significantly increases thermogenesis and lipid use. ${ }^{2,3}$ During only $\beta_{1}$ - or only

From the Nutrition Toxicology and Environment Research Institute Maastricht, Department of Human Biology, Maastricht University. Supported by grant 903-39-138 from the Netherlands Organization for Scientific Research (NWO).

Received for publication Nov 10, 1999; accepted Feb 26, 2000.

Reprint requests: Sandra L. H. Schiffelers, MSc, Department of Human Biology, Maastricht University, PO Box 616, 6200 MD, Maastricht, The Netherlands.

E-mail: S.Schiffelers@hb.unimaas.nl

Copyright () 2000 by Mosby, Inc.

0009-9236/2000/\$12.00 + $0 \quad \mathbf{1 3 / 1 / 1 0 6 7 9 4}$

doi:10.1067/mcp.2000.106794 $\beta_{2}$-adrenergic stimulation, energy expenditure, lipid oxidation, and lipolysis also increase. ${ }^{2,4}$ The role of the $\beta_{3}$-adrenergic receptor in human energy and substrate metabolism is still debated. In rats, $\beta_{3}$-adrenergic stimulation leads to significant increases in thermogenesis and lipid use, which results in weight loss. 5,6 If this is also the case in humans, specific $\beta_{3}$-adrenergic receptor agonists may be seen as potential antiobesity drugs, especially because $\beta_{3}$-adrenergic stimulation causes no tachycardia or tremor. However, the rat $\beta_{3}$-adrenergic receptor differs pharmacologically from the human $\beta_{3}$-adrenergic receptor. ${ }^{7,8}$ Consequently the specific $\beta_{3}$-adrenergic receptor agonists used in rats are only weak agonists in humans. At this time no full $\beta_{3}$-adrenergic receptor agonist is available for administration in humans.

In vitro studies with isolated human fat cells have indicated that the $\beta_{1^{-}}, \beta_{2^{-}}$, and $\beta_{3^{-} \text {-adrenergic receptor }}$ agonist isoproterenol (INN, isoprenaline) induces $\beta_{1}$ - and $\beta_{2}$-adrenergic receptor-mediated lipolysis in 
the nanomolar dose range, whereas $\beta_{3}$-adrenergic receptor-mediated lipolysis is activated at $\sim 100$-fold higher concentrations. ${ }^{9,10}$ In vivo studies with isoproterenol show contradictory results. Isoproterenol infusion leading to nanomolar plasma concentrations predominantly stimulated adipose tissue lipolysis by $\beta_{1}$-adrenergic receptor stimulation because simultaneous $\beta_{1}$-adrenergic receptor blockade with atenolol completely inhibited the increase in plasma free fatty acid and glycerol concentrations. ${ }^{11}$ In another study isoproterenol-induced lipolysis was completely blocked by the $\beta_{1^{-}}$and $\beta_{2^{-}}$ adrenergic receptor antagonist nadolol. ${ }^{3}$ However, energy expenditure significantly increased despite $\beta_{1}$ - and $\beta_{2}$-adrenergic receptor blockade, suggesting $\beta_{3}$-adrenergic receptor-mediated thermogenesis. ${ }^{3}$ The indirectly acting sympathomimetic agent ephedrine significantly increased energy expenditure after pretreatment with a low dose of nadolol, but thermogenesis was completely inhibited after a higher dosage of nadolol. ${ }^{12}$ Norepinephrine-induced thermogenesis completely disappeared after intravenous infusion of the $\beta_{1}$ - and $\beta_{2}$-adrenergic receptor antagonist propranolol. ${ }^{2}$ These studies provide no evidence for a $\beta_{3}$-adrenergic receptor-mediated effect on thermogenesis in humans.

The discrepancies between these studies may be attributable to differences in the type and dose of the $\beta$-adrenergic receptor agonists and antagonists used. To investigate whether the human $\beta_{3}$-adrenergic receptor plays a role in isoproterenol-induced human thermogenesis, two studies were performed. In the first study different dosages of the $\beta_{1}$ - and $\beta_{2}$-adrenergic receptor antagonists nadolol and propranolol were administered to see which minimal dosage is required to block all $\beta_{1}$ - and $\beta_{2}$-adrenergic receptor-mediated effects of a standardized dose of isoproterenol. Furthermore, we investigated whether a significant increase in thermogenesis, lipid use, or both would remain after full $\beta_{1}$ - and $\beta_{2}$-adrenergic receptor blockade, which would provide evidence for a functional role of the human $\beta_{3}$-adrenergic receptor. In the second study, isoproterenol was given at a twofold to tenfold higher infusion rate in combination with nadolol to see whether isoproterenol could induce any $\beta_{3}$-adrenergic receptor-mediated effects on thermogenesis and lipid use in vivo at these higher concentrations.

\section{SUBJECTS AND METHODS}

Subjects. Eight healthy men with a mean age of 21.4 years (age range, 19 to 26 years) and a mean body mass index (BMI) of $22.4 \mathrm{~kg} / \mathrm{m}^{2}$ (BMI range, 20.0 to 25.5 $\mathrm{kg} / \mathrm{m}^{2}$ ) participated in the first study. Seven comparable subjects with a mean age of 23.0 years (age range,
20 to 27 years) and a mean body mass index of 22.1 $\mathrm{kg} / \mathrm{m}^{2}$ (BMI range, 20.2 to $25.5 \mathrm{~kg} / \mathrm{m}^{2}$ ) participated in the second study. All subjects were in good health and were taking no medication at the time of the study. The study protocol was approved by the Ethics Committee of Maastricht University, and all subjects gave written informed consent before entering the study.

Experimental protocol. In both studies subjects came to the laboratory after fasting overnight for at least 10 hours. They came by car or public transportation to minimize the amount of physical activity before the tests. On arrival a canula was inserted into a forearm vein of each subject, and the subjects rested in a semisupine position during the remainder of the test. All subjects watched television or videos during the tests. The room temperature was kept between $23^{\circ} \mathrm{C}$ to $25^{\circ} \mathrm{C}$, and there were at least 3 days between tests.

During the first visit in the first study, an incremental isoproterenol dose response test was performed. A 30-minute baseline period was followed by increasing doses of 10,20 , and $40 \mathrm{ng} / \mathrm{kg} \cdot \mathrm{min}$ isoproterenol (isoproterenol sulfate, Fresenius, 's Hertogenbosch, The Netherlands), per dose for 30 minutes. During the test energy expenditure was continuously measured, and heart rate was monitored. When heart rate rose more than 35 beats/min above baseline, isoproterenol infusion was stopped. With linear regression analysis the dose of isoproterenol required for a $25 \%$ increase in energy expenditure was calculated for each subject.

During the eight remaining visits in the first study, subjects took 2.5, 7.5, 15, or $40 \mathrm{mg}$ oral nadolol (Corgard, Bristol-Myers Squibb, Woerden, The Netherlands) or $2.5,7.5,15$, or $40 \mathrm{mg}$ oral propranolol (Inderal, Zeneca, Ridderkerk, The Netherlands) 2 hours before they came to the laboratory. On arrival, a 30-minute baseline period was followed by a 30-minute infusion period in which subjects received their individually determined dose of isoproterenol. The study design was singleblinded for subjects, and the antagonists were given at random. During the test, energy expenditure and the respiratory exchange ratio were continuously measured, and heart rate was monitored. After 20 minutes of each 30minute period, blood pressure and tremor of the dominant hand were measured, and a blood sample was obtained at the end of each 30-minute period.

During the second study subjects ingested $80 \mathrm{mg}$ nadolol 2 hours before arrival at the laboratory. After a baseline period of 30 minutes, a continuous infusion of isoproterenol or saline solution was started. Isoproterenol was infused in increasing dosages of 50, 100, and $200 \mathrm{ng} / \mathrm{kg} \cdot \mathrm{min}$ for 30 minutes each. Saline solution was administered at the same infusion rates. The 
Table I. Baseline values of the measured parameters after pretreatment with nadolol or propranolol

\begin{tabular}{|c|c|c|c|c|c|c|c|c|}
\hline \multirow[b]{2}{*}{ Parameter } & \multicolumn{4}{|c|}{ Nadolol (mg) } & \multicolumn{4}{|c|}{ Propranolol (mg) } \\
\hline & 2.5 & 7.5 & 15 & 40 & 2.5 & 7.5 & 15 & 40 \\
\hline $\mathrm{EE}(\mathrm{kJ} / \mathrm{min})$ & $5.71 \pm 0.17$ & $5.74 \pm 0.18$ & $5.85 \pm 0.17$ & $5.76 \pm 0.22$ & $5.85 \pm 0.21$ & $5.89 \pm 0.24$ & $5.97 \pm 0.24$ & $5.60 \pm 0.19$ \\
\hline RER & $0.87 \pm 0.01$ & $0.86 \pm 0.02$ & $0.86 \pm 0.02$ & $0.87 \pm 0.02$ & $0.84 \pm 0.02$ & $0.86 \pm 0.02$ & $0.86 \pm 0.02$ & $0.82 \pm 0.01$ \\
\hline $\mathrm{FFA}(\mu \mathrm{mol} / \mathrm{L})$ & $279 \pm 45$ & $335 \pm 52$ & $278 \pm 32$ & $272 \pm 32$ & $358 \pm 113$ & $349 \pm 87$ & $264 \pm 32$ & $409 \pm 46$ \\
\hline Glycerol $(\mu \mathrm{mol} / \mathrm{L})$ & $49.9 \pm 3.8$ & $51.9 \pm 3.8$ & $50.4 \pm 3.6$ & $53.6 \pm 4.0$ & $46.2 \pm 4.6$ & $51.9 \pm 3.5$ & $47.9 \pm 3.3$ & $58.2 \pm 3.0$ \\
\hline Lactate $(\mathrm{mmol} / \mathrm{L})$ & $1.35 \pm 0.06$ & $1.25 \pm 0.11$ & $1.45 \pm 0.13$ & $1.44 \pm 0.12$ & $1.52 \pm 0.11$ & $1.37 \pm 0.08$ & $1.43 \pm 0.12$ & $1.17 \pm 0.09$ \\
\hline Potassium (mmol/L) & $4.05 \pm 0.09$ & $4.05 \pm 0.07$ & $4.00 \pm 0.06$ & $4.08 \pm 0.09$ & $3.97 \pm 0.10$ & $4.13 \pm 0.06$ & $4.11 \pm 0.08$ & $3.99 \pm 0.08$ \\
\hline Tremor score & $6.19 \pm 0.92$ & $6.77 \pm 1.72$ & $5.52 \pm 1.02$ & $4.63 \pm 0.70$ & $6.94 \pm 1.47$ & $6.06 \pm 0.82$ & $6.77 \pm 1.31$ & $7.75 \pm 1.52$ \\
\hline Heart rate (beats/min) & $50 \pm 2$ & $49 \pm 3$ & $47 \pm 2$ & $47 \pm 3$ & $52 \pm 3$ & $53 \pm 3$ & $52 \pm 2$ & $49 \pm 3$ \\
\hline Systolic BP (mm Hg) & $114 \pm 3$ & $109 \pm 2$ & $113 \pm 5$ & $113 \pm 3$ & $119 \pm 4$ & $119 \pm 4$ & $116 \pm 3$ & $113 \pm 3$ \\
\hline Diastolic BP (mm Hg) & $75 \pm 3$ & $73 \pm 2$ & $78 \pm 3$ & $74 \pm 2$ & $73 \pm 3$ & $74 \pm 2$ & $72 \pm 2$ & $77 \pm 2$ \\
\hline
\end{tabular}

Data are mean values \pm SEM for eight subjects.

EE, Energy expenditure; RER, respiratory exchange ratio; FFA, free fatty acids; BP, blood pressure.

study design was single-blinded for subjects, and the order of treatments was randomized. The parameters measured were the same as those in study 1, except for tremor of the hand.

Methods. Whole-body energy expenditure and the respiratory exchange ratio were measured by indirect calorimetry with an open-circuit ventilated hood system. ${ }^{13}$ The volume of air drawn through the hood was measured by a dry-gas meter (Schlumberger, Dordrecht, The Netherlands), and the composition of the inflowing and outflowing air was analyzed by a paramagnetic oxygen analyzer (Servomex, Crowborough, England) and an infrared carbon dioxide analyzer (Hartmann and Braun, Hanover, Germany). Airflow rate and the oxygen and carbon dioxide concentrations of the ingoing and outgoing air were used to compute oxygen consumption and carbon dioxide production on-line every 2 minutes through an automatic acquisition system interfaced with a personal computer. Energy expenditure was calculated according to the formula of Weir. ${ }^{14}$ Energy expenditure and respiratory exchange ratio values were averaged over the last 20 minutes and $10 \mathrm{~min}$ utes of each infusion step, respectively, and their mean values were used for further analysis.

Heart rate was also monitored continuously by conventional electrocardiography, and the mean heart rate was calculated during the last 20 minutes of each infusion step. Blood pressure was measured after 20 minutes in each infusion interval by an automatic blood pressure device (Speidel \& Keller, Jungingen, Germany), and the mean value of five measurements was used for further analysis.

Tremor of the dominant hand was determined with a steadiness test (Steadiness tester 32011, Lafayette Instrument Company, Lafayette, Ind) at the end of each infusion period in study 1 . The task of the subjects in this test was to hold a metal-tipped stylus for $15 \mathrm{sec}-$ onds in six progressively smaller hole sizes without touching the sides. If tremor occurred, subjects would touch the sides more often, and the tremor score consequently increased.

Analytical methods. Blood samples for the determination of plasma glycerol and free fatty acid concentrations were preserved in sodium-ethylenediaminetetraacetic acid. Heparinized blood was collected for the determination of plasma lactate and potassium concentrations. Blood samples were immediately centrifuged for 1 minute at $7000 \mathrm{~g}$. Plasma was transferred into microtest tubes, rapidly frozen in liquid nitrogen, and stored at $-70^{\circ} \mathrm{C}$ until further analysis. Plasma free fatty acids concentrations were measured with the NEFA $\mathrm{C}$ kit (99475409, WAKO, Neuss, Germany) (coefficient of variation [CV], 2.6\%) with a Cobas-Fara centrifugal analyzer (Roche Diagnostica, Bern, Switzerland). Plasma glycerol concentrations were measured with a glycerol kit (644200 without triglyceride breakdown step, Boehringer, Mannheim, Germany; CV, 0.9\%), and plasma lactate concentrations were measured by the method of Gutmann and Wahlefeld ${ }^{15}$ (CV, 2.0\%) with a Cobas-Bio centrifugal analyzer (Roche Diagnostica). Plasma potassium concentration was determined by an ion-selective electrode (Salm \& Kipp, Breukelen, The Netherlands; CV, 0.7\%). In each run, standard samples with known concentrations were included for quality control.

Data analysis. Results are presented as mean values \pm SEM. In the first study, for each of the antagonists used, the effect of isoproterenol infusion at the dosages used was assessed by two-way repeated-measurements ANOVA. Post hoc testing was done with a paired $t$ test corrected according to Bonferroni's inequalities. Dif- 

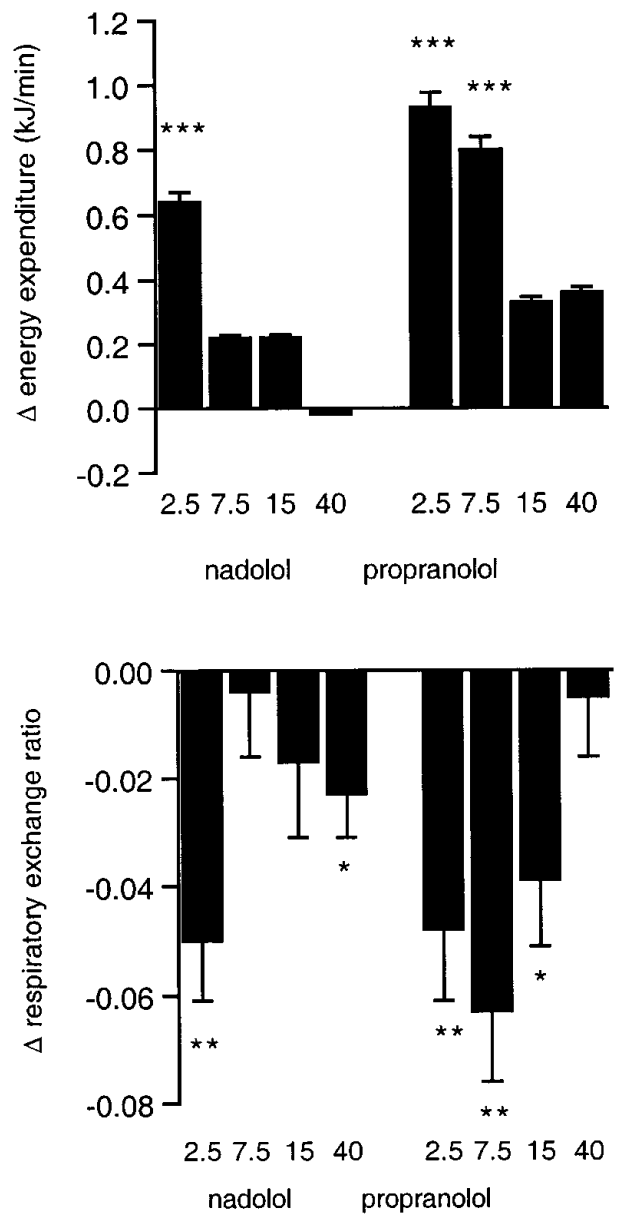

Fig 1. Changes in energy expenditure and respiratory exchange ratio during isoproterenol infusion after pretreatment with $2.5,7.5,15$, or $40 \mathrm{mg}$ nadolol or propranolol (mean $\pm \mathrm{SEM}, \mathrm{n}=8) . * P<.05, * * P<.01, * * * P<.001 \mathrm{com}-$ pared with baseline; Student paired $t$ test.
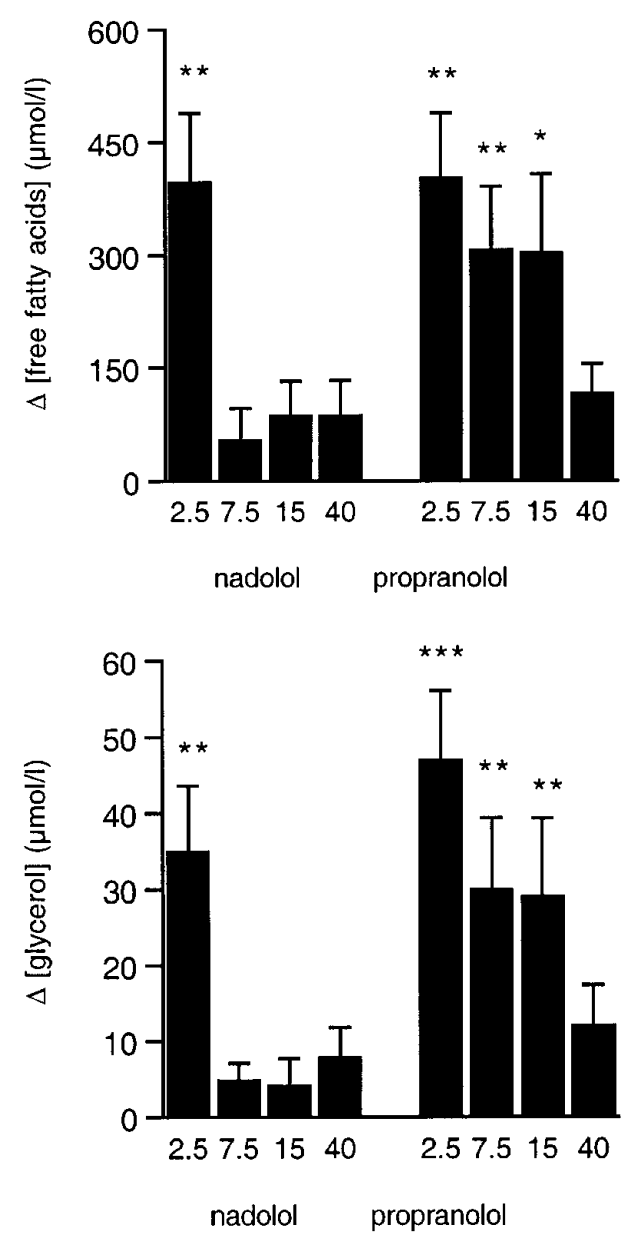

Fig 2. Changes in plasma free fatty acid and glycerol concentrations during isoproterenol infusion after pretreatment with $2.5,7.5,15$, or $40 \mathrm{mg}$ nadolol or propranolol (mean \pm SEM, $\mathrm{n}=8) . * P<.05, * * P<.01, * * * P<.001$ compared with baseline; Student paired $t$ test.

Table II. Changes in plasma lactate and potassium concentrations and tremor score compared with baseline during infusion of isoproterenol after pretreatment with nadolol or propranolol

\begin{tabular}{|c|c|c|c|c|c|c|c|c|}
\hline \multirow[b]{2}{*}{ Parameter } & \multicolumn{4}{|c|}{ Nadolol (mg) } & \multicolumn{4}{|c|}{ Propranolol (mg) } \\
\hline & 2.5 & 7.5 & 15 & 40 & 2.5 & 7.5 & 15 & 40 \\
\hline$\Delta$ Lactate $(\mathrm{mmol} / \mathrm{L})$ & $0.04 \pm 0.06$ & $0.01 \pm 0.05$ & $0.05 \pm 0.05$ & $-0.08 \pm 0.05$ & $0.24 \pm 0.20$ & $0.01 \pm 0.08$ & $-0.01 \pm 0.14$ & $-0.01 \pm 0.04$ \\
\hline$\Delta$ Potassium $(\mathrm{mmol} / \mathrm{L})$ & $-0.03 \pm 0.06$ & $0.07 \pm 0.05$ & $0.03 \pm 0.02$ & $0.04 \pm 0.03$ & $-0.08 \pm 0.10$ & $-0.06 \pm 0.05$ & $-0.08 \pm 0.06$ & $0.10 \pm 0.03$ \\
\hline$\Delta$ Tremor score & $2.38 \pm 1.07$ & $1.38 \pm 0.87$ & $0.21 \pm 0.83$ & $0.92 \pm 0.86$ & $5.31 \pm 1.36^{* *}$ & $3.31 \pm 1.14 *$ & $3.26 \pm 1.55$ & $-1.24 \pm 0.62 *$ \\
\hline
\end{tabular}

Data are mean values \pm SEM for eight subjects.

$* P<.05, * * P<.01$ compared with baseline (Student paired $t$ test)

ferences between the antagonists used were assessed by factorial ANOVA. In the second study, two-way repeated-measurements ANOVA was used to determine significant differences between saline solution and iso- proterenol infusion. Post hoc testing was done with a paired $t$ test. One-way repeated-measurements ANOVA was used to assess differences within a trial. A $P$ value $<.05$ was regarded as statistically significant. 

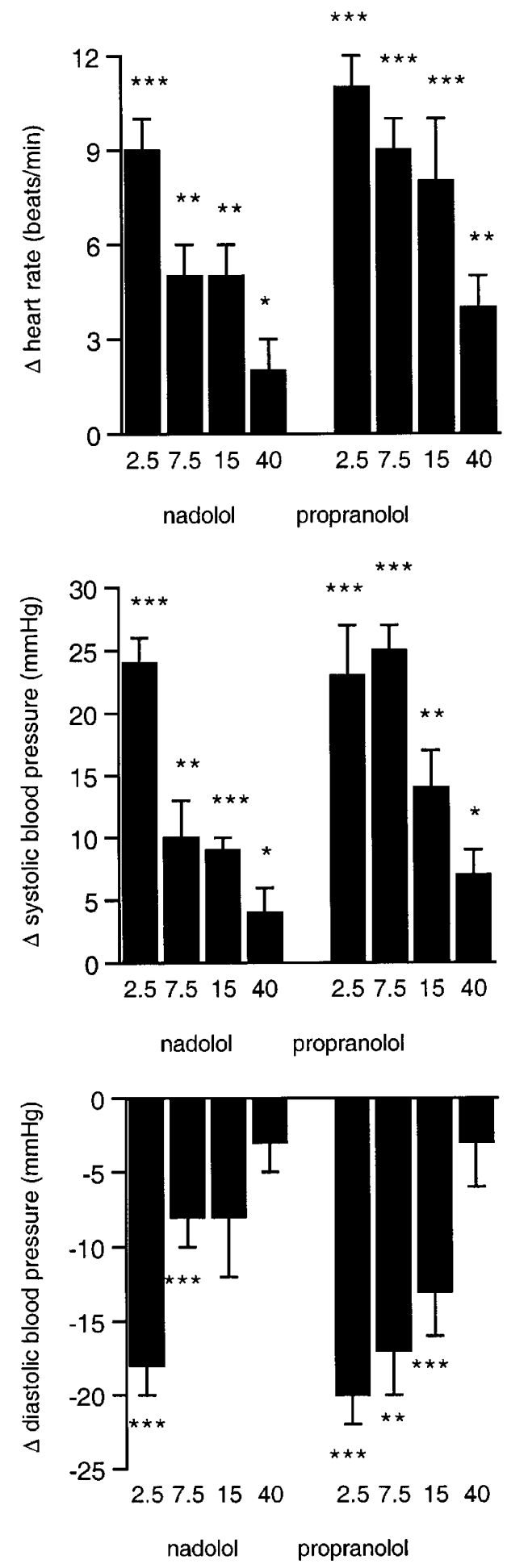

Fig 3. Changes in heart rate and systolic and diastolic blood pressure during isoproterenol infusion after pretreatment with $2.5,7.5,15$, or $40 \mathrm{mg}$ of nadolol or propranolol (mean \pm SEM, $\mathrm{n}=8) . * P<.05, * * P<.01, * * * P<.001$ compared with baseline; Student paired $t$ test.

\section{RESULTS}

First study. The dose of isoproterenol required for a $25 \%$ increase in energy expenditure ranged from 19 to $35 \mathrm{ng} / \mathrm{kg} \cdot \mathrm{min}$, with a mean value of $27 \mathrm{ng} / \mathrm{kg} \cdot \mathrm{min}$.

The dosages of nadolol used in this study had no effect on baseline values of the measured parameters (Table I). After $2.5 \mathrm{mg}$ nadolol, subsequent isoproterenol infusion significantly increased energy expenditure (Fig 1) and plasma free fatty acid and glycerol concentrations (Fig 2), as well as heart rate and systolic blood pressure (Fig 3); it significantly lowered the respiratory exchange ratio (Fig 1) and diastolic blood pressure (Fig 3). Plasma lactate and potassium concentrations and tremor score were not significantly affected (Table II). After pretreatment with $7.5,15$, and $40 \mathrm{mg}$ nadolol, isoproterenol infusion resulted in significant increases in heart rate and systolic blood pressure only and a significant decrease in diastolic blood pressure ( $7.5 \mathrm{mg}$ only) and the respiratory exchange ratio ( $40 \mathrm{mg}$ only). All other parameters remained unchanged.

The dosages of propranolol used did not affect baseline parameters (Table I). Pretreatment with 2.5, 7.5, and $15 \mathrm{mg}$ propranolol led to significant increases in plasma free fatty acid and glycerol concentrations (Fig 2) and heart rate and systolic blood pressure (Fig 3), and it led to significant decreases in the respiratory exchange ratio (Fig 1) and diastolic blood pressure (Fig 3). Energy expenditure (Fig 1) and tremor score (Table II) significantly increased during isoproterenol infusion after pretreatment with 2.5 and $7.5 \mathrm{mg}$ propranolol only but not after 15 and $40 \mathrm{mg}$ propranolol. Plasma lactate and potassium concentrations were not affected by propranolol (Table I). After administration of $40 \mathrm{mg}$ propranolol, isoproterenol infusion still led to significant increases in heart rate and systolic blood pressure and a significant decrease in tremor score.

In summary, both nadolol and propranolol antagonized the changes induced by isoproterenol. At the highest dosages of nadolol and propranolol, still significant changes in heart rate and systolic blood pressure were found during isoproterenol infusion; most other parameters no longer differed significantly from baseline. At the same dose of antagonist, the antagonizing effect of nadolol on changes in the respiratory exchange ratio, plasma free fatty acid concentration, tremor score, systolic blood pressure (factorial ANOVA for antagonist, all $P<.01$ ), and heart rate (factorial ANOVA for antagonist, $P<.001$ ) was more pronounced than the antagonizing effect of propranolol.

Second study. Infusion of saline solution or increasing dosages of isoproterenol significantly increased energy expenditure; plasma free fatty acid, glycerol, 
lactate, and potassium concentrations; heart rate; and systolic blood pressure after pretreatment with $80 \mathrm{mg}$ nadolol. The respiratory exchange ratio significantly decreased and diastolic blood pressure remained unchanged during saline solution or isoproterenol infusion (Fig 4 and Table III).

Only the increase in heart rate was significantly higher during isoproterenol infusion compared with saline solution infusion (two-way repeated-measurements ANOVA for heart rate $\times$ treatment, $P<.001$; Fig 4$)$. The other parameters did not differ between treatments.

\section{DISCUSSION}

The first study was performed to investigate whether any significant increases in isoproterenol-induced thermogenesis, lipid use, or both would remain after full $\beta_{1}$ - and $\beta_{2}$-adrenergic receptor blockade that would provide evidence for a functional role of the human $\beta_{3}$-adrenergic receptor during isoproterenol infusion. To ensure that all $\beta_{1}$-adrenergic receptor-mediated effects of isoproterenol were blocked by nadolol or propranolol, heart rate and systolic blood pressure were measured as indicators for $\beta_{1}$-adrenergic stimulation. ${ }^{16}$ Administration of nadolol or propranolol in a range of 2.5 to $40 \mathrm{mg}$ could not prevent a significant isoproterenol-induced increase in heart rate and systolic blood pressure. This result suggests that no complete $\beta_{1}$-adrenergic receptor blockade was achieved with the dosages of antagonists used. To control for $\beta_{2}$-adrenergic stimulation, plasma lactate and potassium concentrations and tremor score were measured as specific indicators for $\beta_{2}$-adrenergic stimulation. ${ }^{16}$ An isoproterenol-induced increase in tremor score occurred after pretreatment with 2.5 and $7.5 \mathrm{mg}$ propranolol only. Otherwise, no indications for $\beta_{2}$-adrenergic stimulation could be found, indicating that after pretreatment with 2.5 to $40 \mathrm{mg}$ nadolol and 15 and $40 \mathrm{mg}$ propranolol, all $\beta_{2}$-adrenergic receptor-mediated effects of isoproterenol were blocked. Overall, however, no complete $\beta_{1^{-}}$or $\beta_{2}$-adrenergic receptor blockade was achieved after pretreatment with nadolol or with propranolol at dosages $\leq 40 \mathrm{mg}$. This result suggests that the increases in energy expenditure, lipid oxidation, as indicated by a decrease in respiratory exchange ratio, and lipolysis, as indicated by increases in plasma free fatty acids and glycerol concentrations, observed in the first study might be explained by $\beta_{1^{-}}$and/or $\beta_{2}$-adrenergic stimulation, and no evidence can be provided for a functional role of the human $\beta_{3}$-adrenergic receptor in thermogenesis and lipid use during the infusion of $\sim 30$ $\mathrm{ng} / \mathrm{kg} \cdot \mathrm{min}$ isoproterenol.

In the second study, isoproterenol infusion rates were increased to 50, 100, and $200 \mathrm{ng} / \mathrm{kg} \cdot \mathrm{min}$. The nadolol
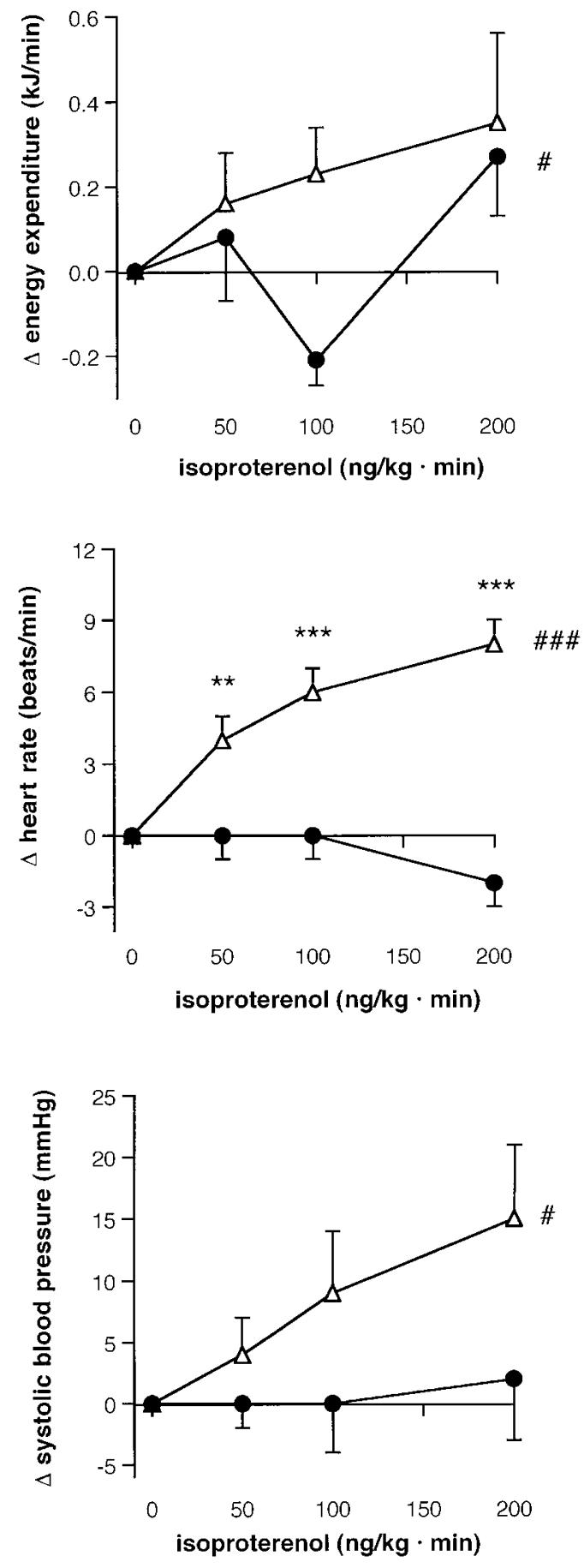

Fig 4. Changes in energy expenditure, heart rate, and systolic blood pressure during saline solution (solid circles) or isoproterenol (INN, isoprenaline; triangles) infusion after pretreatment with $80 \mathrm{mg}$ nadolol (mean $\pm \mathrm{SEM}, \mathrm{n}=7$ ). $\# P<$ .05 , \#\#\# < .001; One-way repeated-measurements ANOVA. $* * P<.01, * * * P<.001$ compared with saline solution; Student paired $t$ test. 
Table III. Changes in measured parameters compared with baseline during infusion of saline solution or isoproterenol after pretreatment with $80 \mathrm{mg}$ nadolol

\begin{tabular}{|c|c|c|c|c|c|}
\hline \multirow[b]{2}{*}{ Parameter and treatment } & \multicolumn{3}{|c|}{ Isoproterenol $(\mathrm{ng} / \mathrm{kg} \cdot \mathrm{min})$} & \multicolumn{2}{|r|}{ ANOVA } \\
\hline & 50 & 100 & 200 & Parameter & Parameter $\times$ treatment \\
\hline \multicolumn{6}{|c|}{$\Delta$ Respiratory exchange ratio } \\
\hline Saline solution & $-0.007 \pm 0.010$ & $-0.015 \pm 0.007$ & $-0.020 \pm 0.006$ & $<.01$ & NS \\
\hline Isoproterenol & $-0.022 \pm 0.005$ & $-0.040 \pm 0.010$ & $-0.031 \pm 0.016$ & & \\
\hline \multicolumn{6}{|l|}{$\Delta$ Free fatty acids $(\mu \mathrm{mol} / \mathrm{L})$} \\
\hline Saline solution & $21 \pm 33$ & $93 \pm 54$ & $100 \pm 65$ & $<.001$ & NS \\
\hline Isoproterenol & $31 \pm 34$ & $98 \pm 42$ & $178 \pm 58$ & & \\
\hline \multicolumn{6}{|l|}{$\Delta$ Glycerol $(\mu \mathrm{mol} / \mathrm{L})$} \\
\hline Saline solution & $3.2 \pm 2.7$ & $11.3 \pm 5.0$ & $18.9 \pm 7.0$ & $<.01$ & NS \\
\hline Isoproterenol & $-6.0 \pm 4.2$ & $0.9 \pm 4.2$ & $5.0 \pm 5.9$ & & \\
\hline \multicolumn{6}{|l|}{$\Delta$ Lactate $(\mathrm{mmol} / \mathrm{L})$} \\
\hline Saline solution & $0.05 \pm 0.03$ & $0.07 \pm 0.04$ & $0.06 \pm 0.04$ & $<.05$ & NS \\
\hline Isoproterenol & $0.01 \pm 0.02$ & $0.04 \pm 0.02$ & $0.04 \pm 0.03$ & & \\
\hline \multicolumn{6}{|l|}{$\Delta$ Potassium $(\mathrm{mmol} / \mathrm{L})$} \\
\hline Saline solution & $0.23 \pm 0.08$ & $0.24 \pm 0.13$ & $0.27 \pm 0.10$ & $<.05$ & NS \\
\hline Isoproterenol & $0.22 \pm 0.12$ & $0.28 \pm 0.13$ & $-0.08 \pm 0.17$ & & \\
\hline \multicolumn{6}{|c|}{$\Delta$ Diastolic blood pressure $(\mathrm{mm} \mathrm{Hg})$} \\
\hline Saline solution & $1 \pm 1$ & $1 \pm 3$ & $2 \pm 3$ & NS & NS \\
\hline Isoproterenol & $-1 \pm 2$ & $1 \pm 3$ & $3 \pm 5$ & & \\
\hline
\end{tabular}

Data are mean values \pm SEM for seven subjects.

dose was increased to $80 \mathrm{mg}$ because the $40 \mathrm{mg}$ nadolol used in the first study did not completely block all $\beta_{1}$-adrenergic receptor-mediated effects on heart rate and systolic blood pressure. Nadolol was chosen because its blocking properties were more pronounced compared with those of propranolol, as shown in the first study, and higher dosages of propranolol might partly block $\beta_{3}$-adrenergic receptors, as shown by Emorine et al. ${ }^{17}$ In the second study, isoproterenol infusion did not cause any significant changes in energy expenditure, lipid oxidation, and lipolysis compared with saline solution infusion. Only a significant increase in heart rate occurred compared with saline solution, which might indicate that nonselective $\beta$-adrenergic stimulation by a high dosage of isoproterenol overcomes $\beta_{1}$-adrenergic receptor blockade. We therefore concluded that after pretreatment with $80 \mathrm{mg}$ nadolol, isoproterenol infusion at a rate $\leq 200 \mathrm{ng} / \mathrm{kg} \cdot \min$ does not provide evidence for a $\beta_{3}$-adrenergic receptormediated increase in thermogenesis and lipid use in vivo in humans. In vitro studies in Chinese hamster ovary cells show that $3.9 \mathrm{nmol} / \mathrm{L}$ isoproterenol is required to produce a half-maximal response for the human $\beta_{3}$-adrenergic receptor. ${ }^{17}$ Plasma levels of $\sim 10 \mathrm{nmol} / \mathrm{L}$ are achieved with an infusion rate of 200 $\mathrm{ng} / \mathrm{kg} \cdot \mathrm{min}$, suggesting that the isoproterenol concentration might have been high enough to find an effect of $\beta_{3}$-adrenergic receptor stimulation.
Wheeldon et $\mathrm{al}^{3}$ performed a similar study. They infused isoproterenol at a rate $(0.5$ to $3.0 \mu \mathrm{g} / \mathrm{min})$ that increased the individual heart rate by 60 beats $/ \mathrm{min}$ and resulted in a 30\% increase in energy expenditure. Pretreatment with 20 and $80 \mathrm{mg}$ nadolol completely blocked $\beta_{1}$-adrenergic receptor-specific changes in heart rate and $\beta_{2}$-adrenergic receptor-specific changes in finger tremor. Concomitant isoproterenol infusion induced a significant $13 \%$ and $10 \%$ increase in thermogenesis after pretreatment with 20 and $80 \mathrm{mg}$ nadolol, respectively, which was considered to be the result of $\beta_{3}$-adrenergic stimulation. The isoproterenol-induced increases in lipid oxidation and lipolysis were completely blocked by 20 and $80 \mathrm{mg}$ nadolol, suggesting that fat metabolism was probably not stimulated by $\beta_{3}$-adrenergic receptors. According to our study, $\beta_{1}$-adrenergic receptors are not fully blocked at the nadolol concentrations used, and the observed increase in thermogenesis might therefore be explained by concomitant $\beta_{1}$-adrenergic stimulation.

Liu et al ${ }^{12}$ performed a study in which ephedrine was given to stimulate the release of norepinephrine from sympathetic nerve endings, leading to high local norepinephrine concentrations. Thirty milligrams of ephedrine produced a $6.6 \%$ increase in energy expenditure. After pretreatment with $2.5 \mathrm{mg}$ nadolol, energy expenditure still significantly increased by $2.3 \%$ after ephedrine administration. After pretreatment with 5 and $10 \mathrm{mg}$ 
nadolol, no changes in energy expenditure were found. All ephedrine-induced changes in heart rate and blood pressure were blocked after pretreatment with $2.5 \mathrm{mg}$ nadolol according to Liu et al, 12 but they neglected to correct for baseline values, which were also affected by nadolol. According to our recalculations, ephedrine induced an increase in systolic blood pressure after pretreatment with $2.5 \mathrm{mg}$ nadolol and an increase in both systolic blood pressure and heart rate with $5 \mathrm{mg}$ nadolol. This result suggests that $\beta_{1}$-adrenergic receptors were not completely blocked with these lower dosages of nadolol, which is in accordance with our findings and those of Wheeldon et al. ${ }^{3}$ The observed significant increase in thermogenesis by Liu et al ${ }^{12}$ might therefore be attributable to concomitant $\beta_{1}$-adrenergic stimulation and not to $\beta_{3}$-adrenergic stimulation.

Finally, Blaak et $\mathrm{al}^{2}$ showed that infusion of the $\alpha$-,

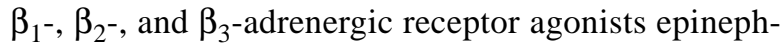
rine (15 to $60 \mathrm{ng} / \mathrm{kg} \cdot \mathrm{min}$ ) or norepinephrine (25 to 100 $\mathrm{ng} / \mathrm{kg} \cdot \mathrm{min}$ ) in combination with propranolol infusion (bolus, $195 \mu \mathrm{g} / \mathrm{kg}$; infusion, $0.6 \mu \mathrm{g} / \mathrm{kg} \cdot \mathrm{min}$ ) did not change energy expenditure but significantly increased mean arterial blood pressure by $\alpha$-adrenergic receptor stimulation and consequently significantly decreased heart rate. Blaak et $\mathrm{al}^{2}$ concluded that the dosages of epinephrine and norepinephrine used could not induce $\beta_{3}$-adrenergic receptor-mediated thermogenesis.

The previously described studies are the only ones published until now that have selectively tried to stimulate $\beta_{3}$-adrenergic receptors. Other studies used relatively unselective $\beta_{3}$-adrenergic receptor agonists to determine the effect of $\beta_{3}$-adrenergic stimulation on human thermogenesis and lipid use in vivo. The thermogenic compound Ro 16-8714 not only increased energy expenditure but also had significant effects on heart rate and systolic blood pressure, indicating that part of its effect was mediated by $\beta_{1}$-adrenergic receptors. ${ }^{18}$ Clinical studies with BRL 26830A showed that this $\beta_{3}$-adrenergic receptor agonist induced not only thermogenesis but also tremor, suggesting additional $\beta_{2}$-adrenergic stimulation. ${ }^{19}$ The $\beta_{3}$-adrenergic receptor agonist BRL 35135 significantly increased thermogenesis and lipid use and also induced a significant decrease in serum potassium concentration, indicating additional $\beta_{2}$-adrenergic stimulation. After pretreatment with $20 \mathrm{mg}$ nadolol, BRL 35135 still caused a small but significant increase in thermogenesis, but lipid oxidation and lipolysis were unaffected. ${ }^{20}$ Because heart rate and blood pressure were not measured in this study, it is unknown whether concomitant $\beta_{1}$-adrenergic stimulation could explain this effect.

Although no clear evidence is available from in vivo studies, we believe that $\beta_{3}$-adrenergic receptors may still play a role in human thermogenesis and lipid use. After the administration of CGP 12177 (selective $\beta_{3}$-adrenergic receptor agonist with $\beta_{1^{-}}$and $\beta_{2}$-adrenergic receptor antagonist properties), significant increases in glycerol release were found both in vitro ${ }^{21,22}$ from omental and abdominal fat cells and in situ ${ }^{23,24}$ from abdominal subcutaneous adipose tissue with the use of the microdialysis technique. The increase in glycerol concentration was only $30 \%$ of that found after isoproterenol administration $21,22,24$ but was not affected by the addition of propranolol, 22,23 indicating that CGP 12177 is a weak but selective $\beta_{3}$-adrenergic receptor agonist. No studies are available on in vivo effects of CGP 12177. Furthermore, several studies have shown that an increase in plasma free fatty acid levels caused by infusion of a lipid or lipid heparin mixture induces increases in lipid oxidation ${ }^{25}$ and thermogenesis. ${ }^{26,27}$ Thus if CGP 12177 or a full $\beta_{3}$-adrenergic receptor agonist is capable of increasing lipolysis to the extent that plasma free fatty acid levels increase, significant effects in lipid oxidation and thermogenesis may be expected.

In conclusion, the data from this study indicate that the dosages of nadolol and propranolol used did not fully block all $\beta_{1}$ - and $\beta_{2}$-adrenergic receptor-mediated effects at the given concentrations of isoproterenol. Furthermore, no evidence could be provided for a $\beta_{3}$-adrenergic receptor-mediated increase in human energy expenditure, lipid oxidation, and lipolysis during isoproterenol infusion at dosages $\leq 200 \mathrm{ng} / \mathrm{kg} \cdot \mathrm{min}$. However, with the development of more selective $\beta_{3}$-adrenergic receptor agonists in the future, a possible role for the $\beta_{3}$-adrenergic receptor in in vivo human thermogenesis and lipid use might still be shown.

We thank Esther Thijssen for her support in conducting the second study and Joan Senden and Jos Stegen for their technical support during analysis of the blood samples.

\section{References}

1. Astrup A, Simonsen L, Bülow J, Madsen J, Christensen NJ. Epinephrine mediates facultative carbohydrateinduced thermogenesis in human skeletal muscle. Am J Physiol 1989;257:E340-5.

2. Blaak EE, van Baak MA, Kempen KP, Saris WHM. Role of $\alpha$ - and $\beta$-adrenoceptors in sympathetically mediated thermogenesis. Am J Physiol 1993;264:E11-7.

3. Wheeldon NM, McDevitt DG, Lipworth BJ. Do $\beta_{3^{-}}$ adrenoceptors mediate metabolic responses to isoprenaline. Q J Med 1993;86:595-600.

4. Schiffelers SLH, Van Harmelen VJA, De Grauw HAJ, Saris WHM, Van Baak MA. Dobutamine as selective $\beta_{1}$-adrenoceptor agonist in in vivo studies on human thermogenesis and lipid utilization. J Appl Physiol 1999;87:977-81. 
5. Arch JR, Wilson S. Prospects for $\beta_{3}$-adrenoceptor agonists in the treatment of obesity and diabetes. Int J Obes 1996;20:191-9.

6. Ghorbani M, Claus TH, Himms-Hagen J. Hypertrophy of brown adipocytes in brown and white adipose tissues and reversal of diet-induced obesity in rats treated with a $\beta_{3}$-adrenoceptor agonist. Biochem Pharmacol 1997;54: 121-31.

7. Liggett SB. Functional properties of the rat and human $\beta_{3}$-adrenergic receptors: differential agonist activation of recombinant receptors in Chinese hamster ovary cells. Mol Pharmacol 1992;42:634-7.

8. Ruffolo RR Jr, Messick K, Horng JS. Interactions of three inotropic agents, ASL-7022, dobutamine and dopamine, with $\alpha$ - and $\beta$-adrenoceptors in vitro. Naunyn Schmiedebergs Arch Pharmacol 1984;326:317-26.

9. Shimizu M, Blaak EE, Lönnqvist F, Gafvels ME, Arner P. Agonist and antagonist properties of $\beta_{3}$-adrenoceptors in human omental and mouse 3T3-L1 adipocytes. Pharmacol Toxicol 1996;78:254-63.

10. Galitzky J, Carpene C, Bousquet Melou A, Berlan M, Lafontan M. Differential activation of $\beta_{1^{-}}, \beta_{2^{-}}$and $\beta_{3^{-}}$ adrenoceptors by catecholamines in white and brown adipocytes. Fundam Clin Pharmacol 1995;9:324-31.

11. Blaak EE, van Baak MA, Kemerink GJ, Pakbiers MT, Heidendal GA, Saris WH. $\beta$-Adrenergic stimulation of energy expenditure and forearm skeletal muscle metabolism in lean and obese men. Am J Physiol 1994;267:E306-15.

12. Liu YL, Toubro S, Astrup A, Stock MJ. Contribution of $\beta_{3}$-adrenoceptor activation to ephedrine-induced thermogenesis in humans. Int J Obes 1995;19:678-85.

13. Schoffelen PF, Westerterp KR, Saris WH, Ten Hoor F. A dual-respiration chamber system with automated calibration. J Appl Physiol 1997;83:2064-72.

14. Weir JB. New methods for calculating metabolic rate with special reference to protein metabolism. J Physiol 1949; 109:1-9.

15. Gutmann I, Wahlefeld AW. L-(+)-Lactate determination with lactate dehydrogenase and NAD. In: Bergmeyer MU, editor. Methods in enzymatic analysis. 2nd ed. New York: Academic Press; 1974. p. 1464-8.

16. Haffner CA, Kendall MJ, Maxwell S, Hughes B. The lipolytic effect of $\beta_{1}$ - and $\beta_{2}$-adrenoceptor activation in healthy human volunteers. Br J Clin Pharmacol 1993;35: 35-9.

17. Emorine LJ, Marullo S, Briend Sutren MM, Patey G, Tate K, Delavier Klutchko C, et al. Molecular characterization of the human $\beta_{3}$-adrenergic receptor. Science 1989;245: 1118-21.

18. Henny C, Schutz Y, Buckert A, Meylan M, Jéquier E, Felber JP. Thermogenic effect of the new $\beta$-adrenoreceptor agonist Ro 16-8714 in healthy male volunteers. Int J Obes 1987;11:473-83.

19. Connacher AA, Bennet WM, Jung RT. Clinical studies with the $\beta$-adrenoceptor agonist BRL 26830A. Am J Clin Nutr 1992;55:258S-61.

20. Wheeldon NM, McDevitt DG, McFarlane LC, Lipworth BJ. $\beta$-Adrenoceptor subtypes mediating the metabolic effects of BRL 35135 in man. Clin Sci 1994;86:331-7.

21. Hoffstedt J, Shimizu M, Sjöstedt S, Lönnqvist F. Determination of $\beta_{3}$-adrenoceptor mediated lipolysis in human fat cells. Obes Res 1995;3:447-57.

22. Lönnqvist F, Krief S, Strosberg AD, Nyberg S, Emorine $\mathrm{LJ}$, Arner P. Evidence for a functional $\beta_{3}$-adrenoceptor in man. Br J Pharmacol 1993;110:929-36.

23. Enocksson S, Shimizu M, Lönnqvist F, Nordenström J, Arner P. Demonstration of an in vivo functional $\beta_{3}$ adrenoceptor in man. J Clin Invest 1995;95:2239-45.

24. Barbe P, Millet L, Galitzky J, Lafontan M, Berlan M. In situ assessment of the role of the $\beta_{1^{-}}, \beta_{2^{-}}$and $\beta_{3}$-adrenoceptors in the control of lipolysis and nutritive blood flow in human subcutaneous adipose tissue. Br J Pharmacol 1996;117:907-13.

25. Kleiber H, Munger R, Jallut D, Tappy L, Felley C, Golay A, et al. Interaction of lipid and carbohydrate metabolism after infusions of lipids or lipid lowering agents: lack of a direct relationship between free fatty acid concentrations and glucose disposal. Diabetes Metab 1992;18: 84-90.

26. Thiebaud D, Acheson K, Schutz Y, Felber JP, Golay A, DeFronzo RA, et al. Stimulation of thermogenesis in men after combined glucose-long-chain triglyceride infusion. Am J Clin Nutr 1983;37:603-11.

27. Jung RT, Shetty PS, James WP. Heparin, free fatty acids and an increased metabolic demand for oxygen. Postgrad Med J 1980;56:330-2. 